\section{RMD Open}

Rheumatic \&

Musculoskeletal Diseases

\title{
Educational needs and preferences of young European clinicians and physician researchers working in the field of rheumatology
}

\author{
Christian Beyer, ${ }^{1}$ Sofia Ramiro, ${ }^{2}$ Francisca Sivera, ${ }^{3}$ Peter Mandl, ${ }^{4}$ Pedro M Machado, ${ }^{5}$ \\ Caroline Ospelt, ${ }^{6}$ Anna Moltó, ${ }^{7}$ Helga Radner, ${ }^{4}$ Annamaria lagnocco, ${ }^{8}$ \\ Johannes W Bijlsma, ${ }^{9}$ Ingrid E Lundberg, ${ }^{10}$ The EMEUNET country liaisons group
}

To cite: Beyer C, Ramiro S, Sivera $\mathrm{F}$, et al. Educational needs and preferences of young European clinicians and physician researchers working in the field of rheumatology. RMD Open 2016;2: 0000240 . doi:10.1136/rmdopen-2015000240

- Prepublication history and additional material is available. To view please visit the journal (http://dx.doi.org/ 10.1136/rmdopen-2015000240)

Received 7 January 2016 Revised 7 May 2016 Accepted 12 May 2016

CrossMark

For numbered affiliations see end of article.

Correspondence to Dr Christian Beyer; christian.beyer@uk-erlangen.de

\section{ABSTRACT}

Objectives: To understand the educational needs and preferences of young clinicians and physician researchers in the field of rheumatology in Europe.

Methods: An international online survey was performed as a joint venture of ESCET and EMEUNET. The survey assessed the acceptance of and the access to the current European League Against Rheumatism (EULAR) educational portfolio, as well as the unmet educational needs and learning preferences among individuals below the age of 40 years working in rheumatology in Europe.

Results: Among 568 European clinicians and physician researchers, $65 \%$ indicated that the existing EULAR educational portfolio adequately covers their educational needs. Within the EULAR portfolio, the online course on rheumatic diseases and the postgraduate course were the most appreciated. Participants were very much in favour of new educational courses on imaging techniques, and $63 \%$ of participants indicated a particular interest in musculoskeletal ultrasound. A strong interest in refresher $(60 \%)$ and general review $(55 \%)$ courses was observed. Lack of funding was considered the major obstacle to participating in existing EULAR programmes. Finally, participants showed diverse preferences regarding learning modalities with common interests in live courses and conferences. Conclusions: EULAR's training opportunities are well appreciated among young clinicians and physician researchers in rheumatology. The results from this survey will help to develop EULAR's future educational portfolio.

\section{INTRODUCTION}

Diligent medical education and scientific training in rheumatology enables young clinicians and physician researchers to provide the highest standards of care and develop new treatment strategies for patients with rheumatic and musculoskeletal diseases.

\section{Key messages}

What is already known about this subject?

- Emerging EULAR network (EMEUNET) and EULAR standing committee for education and training (ESCET) conducted the first systematic educational survey on the needs and preferences of young individuals working in the field of rheumatology in Europe.

What does this study add?

- Young clinicians and physician researchers appreciated European League Against Rheumatism (EULAR's) current educational portfolio.

- Participants were very much in favour of new educational courses on imaging techniques, as well as general review and refresher courses.

- Lack of funding was considered the major obstacle to participating in existing EULAR programmes.

How might this impact on clinical practice?

- The results from this survey will help to develop EULAR's future educational portfolio.

Well-trained young individuals are essential for the prosperity of the European rheumatology community, prompting the European League Against Rheumatism (EULAR) to identify education and training as one of its key strategic activities. ${ }^{1}$ In addition to countryspecific schedules that govern the educational standards of young individuals, ${ }^{1-4}$ EULAR offers courses and educational materials that cover niches or complement national training programmes. ${ }^{1}$

Medical care in rheumatology is changing rapidly, which creates new educational needs. In addition, novel training technologies are evolving quickly. Online courses and podcasts 
can bring knowledge from world-leading experts to the offices of young individuals worldwide. Almost 10 years ago, EULAR launched the first online course on rheumatic diseases, which has become one of EULAR's most successful training programmes. ${ }^{1}$

The rapid changes in medical care and learning technologies prompted us to reach out to a large number of young European physicians and scientists working in the field of rheumatology to assess (1) the awareness and acceptance of the current EULAR portfolio, (2) the access to EULAR training opportunities and (3) the unmet educational needs.

\section{METHODS}

\section{Development and distribution of the survey}

The survey was a joint venture of the EULAR standing committee for education and training (ESCET) and the Emerging EULAR network (EMEUNET). The EMEUNET education subgroup piloted the survey, which was reviewed by the EMEUNET working group and ESCET. The final version of the survey was uploaded on SurveyMonkey (complete survey available on request) and email invitations were sent to all EMEUNET members. In addition, EMEUNET country liaisons distributed invitations within national groups of young clinicians and researchers. After the initial invitation, three reminders were sent using the same distribution strategy. Individuals below the age of 40 years performing clinical and/or scientific work in the field of rheumatology were asked to participate. The intended time length of the survey was a maximum of 15 min to ensure high participation and completion rates. The survey mainly assessed categorical responses. At the end of each assessment (eg, awareness of educational programmes or access to educational programmes), participants were invited to provide additional open comments. Data were collected between November 2013 and March 2014.

\section{Data handling}

For all participants, individual responses were checked for completeness. If respondents did not fully answer the questions on basic characteristics including demographics, work and research focus, they were excluded from further analysis. For the specific assessments of clinical or scientific educational needs, participants were allowed to complete or skip the respective section in order to avoid unnecessary questions.

All participants were categorised as 'clinician', 'researcher' or 'physician researcher', with the latter performing both research and clinical work. Clinicians and physician researchers were further categorised according to: (1) clinical position and (2) country of origin, which was further allocated to one of the three following groups according to the gross domestic product (GDP) per capita $2014^{5}$ as follows: Group 1: Norway, Switzerland, Denmark, Sweden, Ireland, the Netherlands, Austria, Belgium, Germany, UK, France,
Italy, Andorra; Group 2: Spain, Cyprus, Malta, Slovenia, Portugal, Greece, Estonia, Czech Republic, Slovakia, Lithuania, Latvia, Poland, Hungary; Group 3: Croatia, Russia, Turkey, Romania, Belarus, Azerbaijan, Bulgaria, Serbia, Albania, Georgia, Ukraine, Moldova.

\section{Statistical analysis}

Of a total of 773 participants, 728 completed the questions on basic characteristics and were included in the first analysis. Given the different background and educational needs, participants from outside Europe and those whose work status was 'researcher' were then excluded, resulting in a selection of young European clinicians and physician researchers. Categorical variables were compared across groups with the $\chi^{2}$ test. Continuous variables were compared across three groups using one-way analysis of variance (ANOVA). For all analyses, $\mathrm{p}$ values $<0.05$ were considered significant. Statistical analysis was carried out using IBM SPSS Statistics V.21 (IBM Deutschland GmbH, Ehningen, Germany) and GraphPadPrism V.5.03 (GraphPad Software, San Diego, California, USA). Open answers and comments were not analysed systematically.

\section{RESULTS}

\section{Characteristics of participants}

Ninety per cent of all participants were from Europe $(\mathrm{N}=656)$, with the highest number of respondents coming from Spain (14\%) and France $(8 \%)$ (see online supplementary table $\mathrm{S} 1$ ). We observed a female predominance $(68 \%)$, and most of the participants were between 25 and 35 years $(76 \%)$ of age (see online supplementary table S2). Most participants' work status was 'physician researcher' (53\%), defined as someone who performs both clinical work and research, followed by 'clinician' (34\%) and 'researcher' (13\%) (see online supplementary table S2). In their clinical work, most participants were trainees or young consultants in rheumatology $(90 \%)$. The majority of participants hold a research position as a $\mathrm{PhD}$ candidate, postdoctoral or junior researcher $(86 \%)$, while only a few Master's students or senior researchers participated in the survey (see online supplementary table S2). A total of 568 participants were included in the detailed analysis after excluding 72 participants from non-European countries and 88 non-clinical scientists.

Regarding their daily schedule, clinicians spent 74 $\pm 18 \%$ of their time in clinical work. Physician researchers also spent most of their time in clinical work (59 $\pm 22 \%$ ) while they used $23 \pm 20 \%$ of their time for research (see online supplementary figure S1). Overall, participants dedicated less time to teaching $(14 \pm 13 \%)$ and little time to administration $(5 \pm 9 \%)$. While physician researchers performed clinical/epidemiological $(78 \%)$, basic $(24 \%)$ and/or translational research (17\%), most clinicians $(51 \%)$ did not carry out research. Asked about their career plans, clinicians and physician 
researchers both showed the highest interest in pursuing a clinical career, followed by an academic career or career in private practice. Both clinicians and physician researchers indicated little interest in working in industry, independent from their clinical position (see online supplementary table S4).

\section{Awareness and access to existing educational}

\section{programmes}

The general awareness of the existing educational programmes under the EULAR umbrella was high for the well-established programmes, although the participation rates were modest. Thirty-two per cent of all participants had already participated in the EULAR online course on rheumatic diseases and $13 \%$ in the EULAR postgraduate course (table 1A). The participation rate in the EULAR online course on rheumatic diseases was similar between trainees in rheumatology and young consultants, the most frequent clinical positions held by the survey participants. In contrast, participation of young consultants at the EULAR postgraduate course, a live course, exceeded that of trainees in rheumatology (table 1B, C).

Table 1 Awareness of existing programmes

\begin{tabular}{|c|c|c|c|c|c|c|c|}
\hline $\begin{array}{l}\text { Characteristic } \\
\text { Clinicians and physician } \\
\text { researchers }\end{array}$ & $\begin{array}{l}\text { Have } \\
\text { never } \\
\text { heard of } \\
\mathrm{N}(\%)\end{array}$ & $\begin{array}{l}\text { Have } \\
\text { heard of } \\
N(\%)\end{array}$ & $\begin{array}{l}\text { Would like to } \\
\text { participate in } \\
N(\%)\end{array}$ & $\begin{array}{l}\text { Have strong } \\
\text { interest in } \\
\mathrm{N}(\%)\end{array}$ & $\begin{array}{l}\text { Have } \\
\text { participated } \\
\text { in } \\
\mathrm{N}(\%)\end{array}$ & $\begin{array}{l}\Sigma \\
N(\%)\end{array}$ & $\begin{array}{l}\chi^{2}, \\
\mathrm{p} \text { value }\end{array}$ \\
\hline \multicolumn{8}{|l|}{ (a) All participants } \\
\hline EULAR online course & $55(10)$ & 78 (14) & $112(21)$ & $125(23)$ & $174(32)$ & $544(100)$ & NA \\
\hline $\begin{array}{l}\text { EULAR online course on } \\
\text { Connective Tissue Diseases }\end{array}$ & $79(15)$ & $146(27)$ & $146(27)$ & $155(29)$ & $18(3)$ & & \\
\hline $\begin{array}{l}\text { EULAR/EUSTAR online course } \\
\text { on SSc }\end{array}$ & $87(16)$ & $161(30)$ & $146(27)$ & $122(22)$ & $28(5)$ & & \\
\hline EULAR ultrasound online course & $93(17)$ & $134(25)$ & $117(22)$ & $152(28)$ & $48(9)$ & & \\
\hline EULAR postgraduate course & $118(22)$ & $125(23)$ & $107(20)$ & $121(22)$ & $73(13)$ & & \\
\hline EULAR epidemiology course & $141(26)$ & $178(33)$ & $110(20)$ & $84(15)$ & $31(6)$ & & \\
\hline $\begin{array}{l}\text { ACR/EULAR exchange } \\
\text { programme }\end{array}$ & $208(38)$ & $142(26)$ & $89(16)$ & $98(18)$ & $7(1)$ & & \\
\hline $\begin{array}{l}\text { EUREKA course of Translational } \\
\text { Medicine }\end{array}$ & $277(51)$ & $130(24)$ & $83(15)$ & $46(9)$ & $8(2)$ & & \\
\hline EUSTAR SSc course & $187(34)$ & $139(26)$ & $92(17)$ & $98(18)$ & $28(5)$ & & \\
\hline EULAR course on capillaroscopy & $127(23)$ & 159 (29) & $114(21)$ & $121(22)$ & $23(4)$ & & \\
\hline EULAR ultrasound course & 78 (14) & $112(21)$ & $107(20)$ & $197(36)$ & $50(9)$ & & \\
\hline \multicolumn{8}{|c|}{ (b) EULAR online course-clinical position } \\
\hline Medical student & $3(38)$ & $2(25)$ & $3(38)$ & $0(0)$ & $0(0)$ & $8(100)$ & $<0.001$ \\
\hline Trainee (internal m.) & $6(14)$ & $9(21)$ & $11(25)$ & $9(21)$ & $9(21)$ & $44(100)$ & \\
\hline Trainee (rheum.) & $32(11)$ & $34(11)$ & $54(18)$ & $79(26)$ & $102(34)$ & $301(100)$ & \\
\hline Young consultant & $14(7)$ & $33(17)$ & $44(23)$ & 37 (19) & $63(33)$ & $191(100)$ & \\
\hline \multicolumn{8}{|c|}{ (c) EULAR postgraduate course_clinical position } \\
\hline Medical student & $4(50)$ & $4(50)$ & $0(0)$ & $0(0)$ & $0(0)$ & $8(100)$ & $<0.001$ \\
\hline Trainee (internal $\mathrm{m}$.) & $20(45)$ & $7(16)$ & $9(20)$ & $5(11)$ & $3(7)$ & $44(100)$ & \\
\hline Trainee (rheum.) & $74(25)$ & $65(22)$ & $60(20)$ & $73(24)$ & $29(10)$ & $301(100)$ & \\
\hline Young consultant & $20(11)$ & $49(26)$ & $38(20)$ & $43(23)$ & $41(22)$ & $191(100)$ & \\
\hline \multicolumn{8}{|c|}{ (d) EULAR online course-country of origin } \\
\hline Group 1 & $27(12)$ & $40(18)$ & $50(23)$ & $40(19)$ & $65(29)$ & $222(100)$ & 0.118 \\
\hline Group 2 & $23(10)$ & $31(14)$ & $45(20)$ & $56(25)$ & $74(32)$ & $229(100)$ & \\
\hline Group 3 & $4(4)$ & $7(8)$ & $17(19)$ & 29 (32) & $35(38)$ & $92(100)$ & \\
\hline \multicolumn{8}{|c|}{ (e) EULAR postgraduate course-country of origin } \\
\hline Group 1 & 79 (35) & $59(27)$ & $33(15)$ & $39(18)$ & $12(5)$ & $222(100)$ & $<0.001$ \\
\hline Group 2 & $32(14)$ & $53(23)$ & $51(22)$ & $54(24)$ & $39(17)$ & $229(100)$ & \\
\hline Group 3 & $7(8)$ & $12(13)$ & $23(25)$ & $28(30)$ & $22(24)$ & $92(100)$ & \\
\hline
\end{tabular}

(a-e) Total sample with $\mathrm{N}=656$ participants of whom 544 responded to this part of the survey. Values are expressed as absolute numbers and percentages in brackets as $\mathrm{N}(\%)$.

(a) Analysis with all responses. (b, c) Analysis on categorisation of participants according to clinical position. (d, e) Analysis on categorisation of participants according to country of origin. Countries allocated to groups 1-3 according to the GDP per capita 2014. Group 1: Norway, Switzerland, Denmark, Sweden, Ireland, the Netherlands, Austria, Belgium, Germany, UK, France, Italy, Andorra; Group 2: Spain, Cyprus, Malta, Slovenia, Portugal, Greece, Estonia, Czech Republic, Slovakia, Lithuania, Latvia, Poland, Hungary; Group 3: Croatia, Russia, Turkey, Romania, Belarus, Azerbaijan, Bulgaria, Serbia, Albania, Georgia, Ukraine, Moldova.

ACR, American College of Rheumatology; EULAR, European League Against Rheumatism; EUSTAR, European Scleroderma Trial and Research Organization; GDP, gross domestic product; internal m, internal medicine; NA, not applicable; rheum, rheumatism; SSc, systemic sclerosis. 
Of note, participation rates in the EULAR online course on rheumatic diseases and the EULAR postgraduate course were higher among young individuals from countries with a lower GDP (group 3; table 1D, E). This trend was reversed, however, for the more competitive programmes, such as the ACR/EULAR exchange programme and the EUREKA course of Translational medicine, although the very low numbers of participants in these training opportunities do not allow one to draw final conclusions (see online supplementary figure S9).

The current EULAR educational programme was very well received by the survey participants: a majority of $64 \%$ disagreed with the statement that the EULAR educational programme did not cover their needs, while

Table 2 Access to existing programmes

\begin{tabular}{llllllll}
\hline & Fully & Mostly & Partially & Do not & & & \\
Characteristic & agree & agree & agree & agree & Undecided $\Sigma$ & $\chi^{2}$, \\
Clinicians and physician researchers & $\mathbf{N}(\%)$ & $\mathbf{N}(\%)$ & $\mathbf{N}(\%)$ & $\mathbf{N}(\%)$ & $\mathbf{N}(\%)$ & $\mathbf{N}(\%)$ & p value \\
\hline
\end{tabular}

(a) All participants

I do not have enough and timely

information about ongoing projects

I cannot afford my educational needs on

my own

My department does not provide me

enough leave to participate in

I do not have access to departmental/

institutional funding

I do not have access to alternative means

of funding

The current EULAR educational

programme does not cover my

educational needs

(b) I do not have enough and timely information about ongoing projects-clinical position

$61(11) \quad 116(22)$

187 (35.1)

$144(27.0) \quad 25(5)$

533 (100) NA

$157(30) \quad 151(28)$

130 (24)

75 (14)

20 (4)

69 (13) 100 (19)

169 (32)

178 (33)

17 (32)

$105(20) \quad 135(25)$

$151(28)$

$114(21)$

28 (5)

74 (14) $132(25)$

176 (33)

127 (24)

24 (5)

14 (3) 25 (4.7)

88 (17)

341 (64)

65 (12)

$6(100)$
$43(100)$
$297(100)$
$187(100)$

187 (100)

$6(100)<0.001$

$43(100)$

$297(100)$

187 (100)
Medical student

Trainee (internal m.)

Trainee (rheum.)

Young consultant

(c) I cannot afford

Medical student

Trainee (internal $\mathrm{m}$.)

Trainee (rheum.)

Young consultant

$1(17) \quad 1(17) \quad 1(17) \quad 3(50)$

$7(16) \quad 10(23) \quad 15(35)$

$39(13) \quad 68(23) \quad 107(36)$

$15(8) \quad 37(20) \quad 64(34)$

my own-clinical position

Medical student

Trainee (internal m.)

Trainee (rheum.)

Young consultant

1 (17)

$11(26)$

$93(30)$

1 (17)

2 (33)

14 (33)

12 (28)

52 (28) $52(28)$

70 (22)

46 (25)

$52(28)$

$\begin{array}{ll}0(0) & 1(17)\end{array}$

0 (0)

$10(3)$

3 (7)

$16(5)$

5 (3)

1 (17)

5 (12)

52 (18)

30 (16)

9 (21)

0 (0)

2 (5)

67 (23)

67 (36)

16 (5)

4 (2)

0 (0)

2 (5)

2 (33)

$42(14)$

31 (17)

$4(9)$

8 (3)

$6(3)$

eds-clinical position

(e) I do not have enough and timely information about ongoing projects-country of origin

Group 1

Group 2

22 (10) $52(24)$

29 (13)

$47(21)$

$81(38)$

77 (34)

10 (11)

17 (19)

29 (32)

(f) $/$ cannot

Group 1

Group 2

Group 3

(17) -country of origin

$37(17) \quad 71(33) \quad 61(28)$

72 (32)

65 (29)

$52(23)$

48 (52)

15 (16)

17 (19)

$3(50)$

$27(63)$

8 (19)

38 (13)

$16(9)$

$181(61)$

$132(71)$

16 (9)

49 (23)

61 (27)

12 (6)

34 (37)

$11(5)$

2 (2)

36 (17)

28 (12)

11 (5)

11 (12) 1 (1)

$<0.001$

$6(100)<0.001$

$43(100)$

297 (100)

187 (100)

216 (100)

0.525

225 (100)

$92(100)$

$216(100)$

$8(4) \quad 225(100)$

92 (100)

0.525

$216(100)$

34 (16)

$132(61)$

23 (10)

225 (100)

0.690

Group 2

6 (3)

$11(5)$

32 (14)

$153(68)$

8 (9)

$92(100)$

$(\mathrm{a}-\mathrm{g})$ Total sample with $\mathrm{N}=656$ participants of whom 533 responded to this part of the survey. Values are expressed as absolute numbers and percentages in brackets as $\mathrm{N}(\%)$.

(a) Analysis with all responses. (b-d) Analysis on categorisation of participants according to clinical position. (e-g) Analysis on categorisation of participants according to country of origin. Countries allocated to groups 1-3 according to the GDP per capita 2014. Group 1: Norway,

Switzerland, Denmark, Sweden, Ireland, The Netherlands, Austria, Belgium, Germany, UK, France, Italy, Andorra; Group 2: Spain, Cyprus,

Malta, Slovenia, Portugal, Greece, Estonia, Czech Republic, Slovakia, Lithuania, Latvia, Poland, Hungary; Group 3: Croatia, Russia, Turkey,

Romania, Belarus, Azerbaijan, Bulgaria, Serbia, Albania, Georgia, Ukraine, Moldova.

EULAR, European League Against Rheumatism; GDP, gross domestic product; NA, not applicable. 
only $3 \%$ were in full agreement (table $2 \mathrm{~A})$. Acceptance rates were even higher among young consultants with up to $71 \%$ disagreeing with the aforementioned statement (table 2D). Lack of funding opportunities was considered the predominant obstacle to participation: $58 \%$ of participants fully or mostly agreed that they cannot afford their educational needs on their own. In addition, $45 \%$ fully or mostly agreed that they do not have access to institutional funding, and $39 \%$ that they do not have enough alternative means of funding (table 2A). In this regard, trainees in internal medicine, trainees in rheumatology and young consultants indicated a similar lack of funding for their educational needs (table 2C). As expected, individuals from countries with a lower GDP more frequently experienced problems with course funding (table 2F). Finally, participants considered lack of timely information about ongoing educational opportunities and lack of leave from work as minor obstacles to participating in the EULAR educational programme (table 2A-G).

\section{Interests and needs of participants}

When asked about their needs and interests, participants were allowed to skip the clinical or scientific assessment. Nevertheless, clinicians and physician researchers showed high interest in clinical (91\%) and scientific
(81\%) educational programmes (data not shown). Regarding dedicated clinical courses, the majority of participants indicated interest or strong interest in imaging studies, including X-ray $(90 \%)$, ultrasound $(88 \%)$ and MRI $(87 \%)$, as well as for refresher courses $(97 \%)$ and general review (95\%) (table 3). When asked about scientific training, responses from the participants were more diverse: interest or strong interest was expressed particularly for courses on statistics (85\%), research methodology $(83 \%)$ and presentation skills $(80 \%)$ (table 3$)$.

Finally, we observed a diversity of individual preferences when interviewing participants for their preferred learning modalities. Interests in attending live courses and conferences for learning purposes were higher compared to other learning modalities (see online supplementary table S5). Eighty-five per cent of participants preferred or strongly preferred participation in live courses and $84 \%$ case-oriented and problemoriented learning.

\section{DISCUSSION}

The current survey assessed the educational needs of young individuals in rheumatology to define and foster future educational opportunities. The survey stands out for its large sample size with around 600 participants

Table 3 Interests in specific training programmes

\begin{tabular}{|c|c|c|c|c|c|}
\hline $\begin{array}{l}\text { Characteristic } \\
\text { Clinicians and physician researchers }\end{array}$ & $\begin{array}{l}\text { No interest } \\
\mathbf{N}(\%)\end{array}$ & $\begin{array}{l}\text { Little interest } \\
\mathrm{N}(\%)\end{array}$ & $\begin{array}{l}\text { Interested in } \\
\mathrm{N}(\%)\end{array}$ & $\begin{array}{l}\text { Strong interest } \\
\mathrm{N}(\%)\end{array}$ & $\begin{array}{l}\Sigma \\
\mathbf{N}(\%)\end{array}$ \\
\hline \multicolumn{6}{|l|}{ (a) Clinical training programmes } \\
\hline \multicolumn{6}{|l|}{ Specific techniques } \\
\hline Communication skills & $59(12)$ & $135(28)$ & $187(39)$ & $96(20)$ & $477(100)$ \\
\hline Clinical examination & $22(4)$ & $54(11)$ & $197(41)$ & $204(43)$ & \\
\hline Capillaroscopy & $42(9)$ & $115(24)$ & $175(37)$ & $145(30)$ & \\
\hline Arthrocentesis & $38(8)$ & $83(17)$ & $166(35)$ & $190(40)$ & \\
\hline Synovial fluid analysis & $30(6)$ & $96(20)$ & $205(43)$ & $146(30)$ & \\
\hline Urine analysis & $107(22)$ & $185(39)$ & $129(27)$ & $56(12)$ & \\
\hline Ultrasound & $13(3)$ & $45(9)$ & $120(25)$ & $299(63)$ & \\
\hline X-ray evaluation & $10(2)$ & $40(8)$ & $193(41)$ & $234(49)$ & \\
\hline MRI & $11(2)$ & $48(10)$ & $202(42)$ & $216(45)$ & \\
\hline Laboratory evaluations & $29(6)$ & 79 (17) & $194(41)$ & $175(37)$ & \\
\hline Biopsy & $42(2)$ & $101(21)$ & 169 (35) & $165(35)$ & \\
\hline \multicolumn{6}{|l|}{ General courses } \\
\hline Review courses on rheumatic diseases & $5(1)$ & $19(4)$ & $190(40)$ & $263(55)$ & \\
\hline Refreshers/updates & $5(1)$ & $8(2)$ & $176(37)$ & $288(60)$ & \\
\hline \multicolumn{6}{|l|}{ (b) Scientific training programmes } \\
\hline General background & $10(2)$ & $69(16)$ & $220(52)$ & $122(29)$ & $421(100)$ \\
\hline Experimental techniques & $36(6)$ & $117(28)$ & $183(44)$ & $109(20)$ & \\
\hline Research methodology (epidemiology, etc) & $15(4)$ & $59(14)$ & $197(47)$ & $150(36)$ & \\
\hline Writing skills & $17(4)$ & $67(16)$ & $199(47)$ & $138(33)$ & \\
\hline Reviewing skills & $19(5)$ & 59 (14) & $201(48)$ & $142(34)$ & \\
\hline Presentation skills & $18(4)$ & $68(16)$ & $172(41)$ & $163(39)$ & \\
\hline Statistics (theory and practice) & $12(3)$ & $50(12)$ & $170(40)$ & $189(45)$ & \\
\hline
\end{tabular}


from 38 European countries. We addressed a broad spectrum of educational details and obtained the following key findings:

1. The current educational portfolio of EULAR is well perceived among young individuals in the field, which is in line with results from a small previous study. ${ }^{3}$ Bandinelli $e t a \hat{l}$ observed a very high acceptance rate for the EULAR online course on rheumatic diseases among 170 young rheumatologists across Europe. Together, these findings reinforce EULAR's educational policy.

2. Lack of financial means is the major obstacle preventing participation in existing EULAR educational programmes. As expected, lack of funding opportunities is a greater issue in countries with a lower GDP per capita. Along with our findings, Gaujoux-Viala et at revealed financial support by bursaries as one of the most important needs of 243 young rheumatologists. To compensate for these financial needs, EULAR has reduced the costs for the online courses and offers course bursaries for its live courses. Future funding opportunities might include educational funds from government or industry.

3. The outstanding interest in imaging modalities (ultrasound, X-ray, MRI) may prompt EULAR to expand its imaging educational programme even beyond the ultrasound courses. EULAR's future scientific courses might teach statistics, presentation skills and research methodologies, as these were among the main interests of young rheumatologists and researchers.

4. While learning preferences were diverse, live courses and live conferences were very much favoured by our participants. This piece of information may raise EULAR's awareness of 'classical' live teaching programmes, which may not always be replaceable by online teaching opportunities.

5. The survey participants showed a strong interest in pursuing a career in academia and in clinical environments, suggesting that EULAR invests in those young individuals who will represent EULAR and the European rheumatology community in future.

Our survey was subject to structural limitations: First, the proportion of (non-physician) researchers was very small within the study, reflecting that EMEUNET and EULAR mainly represent physicians and physician researchers and compelling us to exclude those individuals for the detailed analyses of this survey. Second, EMEUNET members or individuals linked to the EMEUNET network were more likely to receive invitations and participate in the survey, with $46 \%$ of participants being indeed a member of EMEUNET. This might result in a predominance of academia-oriented responders. Second, using the EMEUNET network to distribute invitations to participate in the survey, we could not determine the number of individuals who had finally received our invitations. Finally, country-specific response rates depended on pre-existing networks for young rheumatologists that helped to invite participants.
Although the use of the EMEUNET network resulted in many limitations of our study, we had already learnt in an earlier study ${ }^{4}$ that this network was the only available approach to reach out to young individuals all over Europe: In a lot of European countries, national associations for medicine and rheumatology could provide neither educational information nor contact details of young individuals working in the field. In this context, we wish that this survey may pioneer future educational studies, which will exceed our current work in completeness and unbiasedness of data by collecting information from nationally registered young individuals in training for rheumatology.

Taken together, this large survey among around 600 young individuals working in the field of rheumatology reveals a high acceptance rate of the current EULAR educational portfolio. Training on novel imaging technologies is among the most important educational needs of these young individuals and cost-effective educational opportunities as well as live courses are much appreciated.

\section{Author affiliations}

${ }^{1}$ Department of Internal Medicine 3 and Institute for Clinical Immunology, University of Erlangen-Nuremberg, Erlangen, Germany

${ }^{2}$ Department of Rheumatology, Leiden University Medical Center, Leiden, The Netherlands

${ }^{3}$ Department of Rheumatology, Hospital General Universitario de Elda, Alicante, Spain

${ }^{4}$ Department of Internal Medicine III, Division of Rheumatology, Medical University Vienna, Vienna, Austria

${ }^{5}$ Rheumatology Department, University College London Hospitals \& MRC Centre for Neuromuscular Diseases, University College London, London, UK

${ }^{6}$ Department of Rheumatology, University Hospital Zurich, Zurich, Switzerland

${ }^{7}$ Rheumatology Department, Paris Descartes University, Cochin Hospital, Assistance Publique-Hôpitaux de Paris, INSERM (U1153): Clinical Epidemiology and Biostatistics, PRES Sorbonne Paris-Cité, France

${ }^{8}$ Rheumatology Unit, Sapienza Università di Roma, Rome, Italy

${ }^{9}$ Utrecht University Medical Center, Utrecht, The Netherlands

${ }^{10}$ Rheumatology Unit, Department of Medicine at the Karolinska University Hospital, Solna, Karolinska Institutet, Stockholm, Sweden

Acknowledgements Special thanks to Gabriela Kluge, EULAR Education Programme manager, for her constant support in performing this survey. Many thanks to all young clinicians and researchers who participated in the online survey.

EMEUNET country liaisons group (collaborators): Antigoni Grigoriou, MRCP, MScRheumatology Department, St George's Hospital NHS FoundationTrust, London, UK; Antonis Fanouriakis, MD, Department of Rheumatology, Clinical Immunology and Allergy, University of Crete, Heraklion, Greece; Axel Hueber, MD, PhD, Department of Internal Medicine 3 and Institute for Clinical Immunology, University of Erlangen-Nuremberg, Erlangen, Germany; Britta Maurer, MD, Division of Rheumatology and Research of Systemic Autoimmune Disease, University Hospital Zurich, Zurich, Switzerland; Carlo A. Scirè, MD, PhD, Epidemiology Unit, Italian Society for Rheumatology, Milan, Italy; Cécile Gaujoux-Viala, MD, PhD, Department of Rheumatology, Nîmes University Hospital, EA2415, Montpellier University, Nîmes, France; Diana Karpec, MD, Clinic of Rheumatology, Traumatology, Orthopedics and Plastic and Reconstructive Surgery, Vilnius University Hospital Santariskiu Clinics, Vilnius, Lithuania; Diane van der Woude, MD, PhD, Department of Rheumatology, Leiden University Medical Center, Leiden, The Netherlands; Doron Rimar, MD, Rheumatology Unit, Faculty of Medicine, Bnai Zion Medical Center, Technion, POB 4940, 31048, Haifa, Israel; Elena Deseatnicova, MD, PhD, Department of Rheumatology and 
Nephrology, State Medical and Pharmaceutical University Nicolae Testemitanu, Chisinau, Republic of Moldova; Elena Nikiphorou, MRCP, MD (Res), Department of Rheumatology, Division of Medicine, Whittington Hospital NHS Trust, London, United Kingdom; Ellen De Langhe, MD, PhD, Department of Rheumatology, University Hospital Leuven, KU Leuven, Leuven, Belgium Espen A. Haavardsholm, MD, PhD, Department of Rheumatology, Diakonhjemmet Hospital, Oslo, Norway; Irina Starodubtseva, MD, PhD, Department of Internal Diseases of the NN Burdenko Voronezh State Medical Academy, Voronezh, Russian Federation; György Nagy, MD, PhD, Department of Rheumatology, Semmelweis University, Faculty of Medicine, Semmelweis University, Budapest 1023, Hungary \& Department of Genetics, Cell and Immunobiology, Faculty of Medicine, Semmelweis University, Budapest 1089 , Hungary, Iuliia V. Biliavska MD, PhD, Department of non-coronarogenic heart diseases and clinical rheumatology, SI NSC "Institute of Cardiology named after acad.M.D. Strazhesko", Kyiv, Ukraine; Jan Sznajd, MD, 2nd Department of Internal Medicine, Jagiellonian University Medical College, Krakow, Poland; Johan A Karlsson, MD, PhD, Department of Clinical Sciences Lund, Section of Rheumatology, Lund University, Lund, Sweden; Julija Zepa, MD, Department of Rheumatology, Pauls Stradins Clinical University Hospital, Riga Stradins University, Riga, Latvia; Karen Cassar, MD, FRCP, Department of Medicine, Mater Dei Hospital, Malta; Ladislav Šenolt, MD, PhD, Prof., Institute of Rheumatology and Department of Rheumatology, 1st Faculty of Medicine, Charles University in Prague, Prague, Czech Republic; Liana Ghukasyan, MD, Department of Rheumatology, Medical Center "Erebouni", Yerevan, Armenia; Marko Barešić, MD, Division of Clinical Immunology and Rheumatology, Department of Internal Medicine, School of Medicine, University Hospital Center Zagreb, Zagreb, Croatia; Mojca Frank-Bertoncelj, MD, PhD, Center of Experimental Rheumatology, University Hospital Zurich and University of Zurich, Schlieren, Switzerland; Nelly Ziade, MD, PhD, Department of Rheumatology, Hotel-Dieu de France and Saint-Joseph University, Beirut, Lebanon; Nino Gobejishvili, MD, Research Institute For clinical medicine, AVERSI clinic, Georgian-American Family Medicine Clinic, Georgia, Tbilisi; Predrag Ostojic, MD, PhD, Institute of Rheumatology, University of Belgrade, Belgrade, Serbia; René Østgård, MD, PhD, Department of Rheumatology, Aarhus University Hospital, Aarhus, Denmark; Rucsandra Dobrota, MD, Department of Internal Medicine and Rheumatology, Dr. I. Cantacuzino Hospital, Carol Davila University of Medicine and Pharmacy, Bucharest, Romania \& Division of Rheumatology and Research of Systemic Autoimmune Disease, University Hospital Zurich, Zurich, Switzerland; Russka Shumnalieva, MD, PhD, Department of Internal Medicine, Clinic of Rheumatology, Medical University - Sofia, Sofia, Bulgaria; Sandra Tälli, MD, Department of Rheumatology, East-Tallinn Central Hospital, Tallinn, Estonia; Sonia Panchal, MD, Department of Rheumatology, University Hospitals of Leicester NHS
Trust, Leicester, United Kingdom; Stefania Volpinari, MD, Department of Internal Medicine-Rheumatology Unit San Marino Hospital State Republic of San Marino; Tuomas Rannio, MD, Rheumatology Department, Central Hospital of Central Finland, Jyväskylä, Finland; Vasco C Romão, MD, Department of Rheumatology, Hospital de Santa Maria, Lisbon Academic Medical Centre, Lisbon, Portugal

Contributors CB, SR, FS, PM, PMM, CO, AM, HR, Al, JWB and IEL contributed to the design of the study, collection of the data, interpretation of the results and writing of the manuscript.

Funding CB: Grant BE 5191/1-1 of the Deutsche Forschungsgemeinschaft. Competing interests None declared.

Provenance and peer review Not commissioned; internally peer reviewed.

Data sharing statement The original and complete data set collected via Survey Monkey is available as a Microsoft Excel file. Please use the following contact: Christian.beyer@uk-erlangen.de.

Open Access This is an Open Access article distributed in accordance with the Creative Commons Attribution Non Commercial (CC BY-NC 4.0) license, which permits others to distribute, remix, adapt, build upon this work noncommercially, and license their derivative works on different terms, provided the original work is properly cited and the use is non-commercial. See: http:// creativecommons.org/licenses/by-nc/4.0/

\section{REFERENCES}

1. Rheumatism ELA. Education. 2015. http://www.eular.org/education training.cfm (accessed 18 Oct 2015)

2. Specialists EUoM. UNION EUROPÉENNE DES MÉDECINS SPÉCIALISTES. 2013. http://www.uems.eu/ (accessed 18 Oct 2015).

3. Bandinelli F, Bijlsma JW, Ramiro MS, et al. Rheumatology education in Europe: results of a survey of young rheumatologists. Clin Exp Rheumatol 2011;29:843-5.

4. Sivera F, Ramiro S, Cikes N, et al. Differences and similarities in rheumatology specialty training programmes across European countries. Ann Rheum Dis 2015;74:1183-7.

5. Eurostat. Minimum wages. 2015. http://ec.europa.eu/eurostat/tgm/ table.do?tab=table\&init=1\&language=en \&pcode=tps00155\&plugin $=1$ (accessed 22 Feb 2016).

6. Gaujoux-Viala C, Knevel R, Mandl P, et al. Who are the young professionals working in the field of rheumatology in Europe and what are their needs? An EMEUNET (EMerging EUlar NETwork) survey. Ann Rheumc Dis 2012;71:1432-3. 